\title{
Defining causality in COVID-19 and neurological disorders
}

\author{
Mark Ellul, ${ }^{1,2,3}$ Aravinthan Varatharaj, ${ }^{4,5}$ Timothy R Nicholson, ${ }^{6}$ \\ Thomas Arthur Pollak, ${ }^{6}$ Naomi Thomas, ${ }^{7,8}$ Ava Easton, ${ }^{9}$ \\ Michael S Zandi, ${ }^{10}$ Hadi Manji, ${ }^{10}$ Tom Solomon, ${ }^{1,2,3}$ Alan Carson, ${ }^{11}$ \\ Martin R Turner (D) , ${ }^{12}$ Rachel Kneen, 1,3,13 Ian Galea (D) , 4,5 \\ Sarah Pett, ${ }^{14,15}$ Rhys Huw Thomas, ${ }^{7,16}$ Benedict Daniel Michael (1) , 1,2,3 \\ CoroNerve Steering Committee
}

\section{When faced with acute neurological presentations in a patient with COVID-19, how confident can one be that SARS-CoV2 is causal?}

\begin{abstract}
Introduction
Clinicians are increasingly recognising neurological presentations occur in some patients. ${ }^{1}$ A case series from Wuhan described associated neurological syndromes (eg, 'dizziness' and 'impaired consciousness'), but with little detail regarding symptomatology, and cerebrospinal fluid (CSF) and neuroimaging findings. ${ }^{2}$ The extent to which these disorders were caused by the virus per se, rather than being complications of critical illness, unmasking of degenerative disease, or iatrogenic effects of repurposed medications is not clear.
\end{abstract}

Numerous case reports have since emerged and, at the time of writing,

${ }^{1}$ NIHR Health Protection Research Unit for Emerging and Zoonotic Infection, Liverpool, UK

${ }^{2}$ Neurology, The Walton Centre NHS Foundation Trust, Liverpool, UK

${ }^{3}$ Institute of Infection and Global Health, University of Liverpool, Liverpool, UK

${ }^{4}$ Clinical Neurosciences, Clinical and Experimental Sciences, Faculty of Medicine, University of

Southampton, Southampton, UK

${ }^{5}$ Wessex Neurosciences Centre, University Hospital Southampton NHS Foundation Trust, Southampton, UK ${ }^{6}$ Institute of Psychiatry Psychology \& Neuroscience (IoPPN), King's College London, London, UK

${ }^{7}$ Translational and Clinical Research Institute, Newcastle University, Newcastle, UK

${ }^{8}$ Royal Victoria Infirmary, Newcastle, UK

${ }^{9}$ Encephalitis Society, Malton, UK

${ }^{10}$ Queen Square Institute of Neurology, University College London, London, UK

${ }^{11}$ Department of Psychiatry, University of Edinburgh, Edinburgh, UK

${ }^{12}$ Nuffield Department of Clinical Neurosciences, Oxford University, Oxford, UK

${ }^{13}$ Neurology, Alder Hey Children's NHS Foundation Trust, Liverpool, UK

${ }^{14}$ Institute for Global Health, University College London, London, UK

${ }^{15}$ MRC CTU at UCL, Institute of Clinical Trials and Methodology, University College London, London, UK ${ }^{16}$ Department of Neurology, Royal Victoria Infirmary, Newcastle, UK

Correspondence to Dr Benedict Daniel Michael, University of Liverpool Institute of Infection and Global Health, Liverpool L69 3BX, UK; benmic@liv.ac.uk published cases include encephalopathy, ${ }^{3}$ encephalitis, ${ }^{4}$ Guillain-Barré syndrome $(\mathrm{GBS})^{5}$ and stroke. ${ }^{6}$ In most of these cases, the virus has been identified in respiratory samples, and in a small number in CSF. So far, the reporting of clinical features has been extremely variable, for example, several cases have claimed to report encephalitis without clear evidence of central nervous system (CNS) inflammation, which would not meet established definitions of the disease.

Whether severe acute respiratory syndrome coronavirus 2 (SARS-CoV2) is associated with neurological manifestations is of critical importance as this may result in substantial morbidity and mortality.

\section{Defining causality}

It is crucial that neurologists and neuropsychiatrists apply a systematic strategy to determine whether there is evidence that SARS-CoV2 is causing these manifestations, whether they are a consequence of severe systemic disease alone, or simply coincidence. In 1965, Hill proposed criteria on which to build an argument for disease causation, which can be applied to COVID $-19 .^{8}$

What is the strength of the association? So far, it appears fairly weak. $>2.5$ million people have been infected with SARS-CoV2 and to date (to the authors' knowledge) there have been only 93 published cases of neurological manifestations (about 5/100 000). However, reported cases are an underestimate of the real incidence, and this underscores the need for proper epidemiological study.

What is the consistency of the association? So far, there have been published reports of neurological manifestations across the globe, including from China, Japan, Italy, France, the USA and the UK. Although the numbers are low, these are not isolated incidences and have occurred throughout the evolution of the pandemic.

To what extent is the relationship specific? The range of neurological manifestations reported in association with SARS-CoV2 is wide, from the CNS through to peripheral nerves. However, in previous pandemics, similar central and peripheral associations have been well recognised. ${ }^{9}$

What can temporality tell us about the association? The delay between infection and the neurological presentation may give a clue to mechanisms. Direct CNS infection might be expected to be contemporaneous with, or shortly after, fever and respiratory symptoms. Parainfectious disease, owing to innate immune responses, such as acute necrotising encephalopathy, usually occurs in the days following infection. Post-infectious syndromes, due to adaptive immune responses, such as GBS, are typically in the few weeks following infection. In most reported cases, respiratory disease has occurred a few days prior to the onset of the neurological syndrome although significant delays between a neurological presentation and COVID-19 diagnosis in some raise the possibility of nosocomial infection.

Hill asks us to look for a biological gradient. In general, those with neurological manifestations have had severe COVID-19 respiratory disease suggesting the possibility that higher viral loads and/ or more fulminant inflammatory responses may be accountable for both.

Is there biological plausibility? Many human viruses can enter the CNS and some coronaviruses exhibit neurotropism in animal models. ${ }^{10}$ The syndromes described so far could plausibly be related to primary infection with SARS-CoV2, although improved understanding of host responses is needed.

Hill asks us to consider the coherence of the evidence. Perhaps our best sources of coherent data are the SARS and Middle East respiratory syndrome (MERS) epidemics: coronaviruses with about $80 \%$ and $50 \%$ homology to SARS-CoV2, respectively. Neurological syndromes were reported in association with both, including acute disseminated encephalomyelitis-like presentations with MERS and encephalopathy/encephalitis with SARS. ${ }^{11}$

Is there any possibility of experimental evidence? The ideal investigational vehicle would be a case control study, but this presents design challenges as exposure is high and we do not yet have validated widespread antibody testing to ascertain seroprevalence. 
Can we learn by analogy with other similar scenarios? Other respiratory viruses, most notably influenza, are wellestablished triggers of CNS damage. During the H1N1 pandemic, neurological syndromes were well described, including acute necrotising encephalopathy bearing striking resemblance to the case recently described with COVID-19. ${ }^{9}$ So, the emergence of neurological disorders associated with pandemic viral infections is less the exception, and more the norm.

\section{Conclusions}

As always, our evidence must be founded on clear and systematic assessment of the clinical syndromes, supported by welldesigned laboratory studies. Cases must be reported in line with clear clinical case definitions, both systematically and transparently, and with honesty about negative or missing results.

These aims are best served by standardisation and centralisation of case reporting, which calls for a truly collaborative approach between neurologists, neuropsychiatrists and allied colleagues.

To address this, we have established the CoroNerve Studies Group as a collaboration between professional bodies in the UK (CoroNerve.com), and similar studies are underway in other countries. However, a joined-up international approach is necessary. To begin this process, a complimentary initiative, the COVID-Neuro Network, through Brain Infections Global, is supporting collaboration among several lower and middle-income countries.

We all must learn the lessons from previous pandemics, and the principles of Bradford Hill if we are to translate these rapidly growing datasets into meaningful advances in our understanding of the neurological complications of COVID-19.

Twitter Timothy R Nicholson @Tim_R_Nicholson, Michael S Zandi @michael_zandi and Benedict Daniel Michael@BenedictNeuro
Acknowledgements CoroNerve Study Management Group: Mark Ellul, Ian Galea, Rachel Kneen, Benedict Michael, Sarah Pett, Naomi Thomas, Rhys Thomas, Ara Varantharaj. CoroNerve Steering Committee: Laura Benjamin, Jonathan Coles, Nicholas WS Davies, Ava Easton, Hadi Manji, David Menon, Craig Smith, Tom Solomon, Michael Zandi.

Collaborators CoroNerve Steering Committee: Laura Benjamin, Jonathan Coles, Nicholas WS Davies, Ava Easton, Hadi Manji, Craig Smith, Tom Solomon, Michael Zandi. RCPsych: A Carson, A David, M Dilley, E Joyce, TR Nicholson, T Pollak, V Voon. ABN: M Turner. BPNA: R Chin. BASP: R Al-Shahi Salman, C Smith. NACCS: J Coles, D Menon. ISARIC: C Semple.

Contributors All authors provided substantive input to the design, drafting and editing of this manuscript.

Funding The authors have received funding from the NIHR, MRC, Academy of Medical Sciences, and the Wellcome Trust. The authors have not declared a specific grant for this research from any funding agency in the public, commercial or not-for-profit sectors.

Competing interests None declared.

Patient and public involvement statement $\mathrm{Dr}$ Ava Easton (CEO of the Encephalitis Society), is the head of PPI within the CoroNerve Study's Steering Group

Patient consent for publication Not required.

Provenance and peer review Commissioned; internally peer reviewed.

\section{(a) OPEN ACCESS}

Open access This is an open access article distributed in accordance with the Creative Commons Attribution Non Commercial (CC BY-NC 4.0) license, which permits others to distribute, remix, adapt, build upon this work non-commercially, and license their derivative works on different terms, provided the original work is properly cited, appropriate credit is given, any changes made indicated, and the use is non-commercial. See: http:// creativecommons.org/licenses/by-nc/4.0/.

(c) Author(s) (or their employer(s)) 2020. Re-use permitted under CC BY-NC. No commercial re-use. See rights and permissions. Published by BMJ.

Check for updates

To cite Ellul M, Varatharaj A, Nicholson TR, et al. J Neurol Neurosurg Psychiatry 2020;91:811-812.

Received 28 April 2020

Revised 1 May 2020
Accepted 1 May 2020

Published Online First 5 June 2020

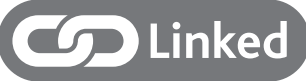

- http://dx.doi.org/10.1136/jnnp-2020-323586

J Neurol Neurosurg Psychiatry 2020;91:811-812. doi:10.1136/jnnp-2020-323667

\section{ORCID iDs}

Martin R Turner http://orcid.org/0000-0003-0267-3180 Ian Galea http://orcid.org/0000-0002-1268-5102 Benedict Daniel Michael http://orcid.org/0000-00028693-8926

\section{REFERENCES}

1 Liu K, Pan M, Xiao Z, et al. Neurological manifestations of the coronavirus (SARS-CoV-2) pandemic 20192020. J Neurol Neurosurg Psychiatry 2020;91:669-70.

2 Mao L, Jin H, Wang M, et al. Neurologic manifestations of hospitalized patients with coronavirus disease 2019 in Wuhan, China. JAMA Neurol 2020. doi:10.1001/ jamaneurol.2020.1127. [Epub ahead of print: $10 \mathrm{Apr}$ 2020].

3 Poyiadji N, Shahin G, Noujaim D, et al. COVID19-associated acute hemorrhagic necrotizing encephalopathy: CT and MRI features. Radiology 2020;201187:201187

4 Ye M, Ren Y, Lv T. Encephalitis as a clinical manifestation of COVID-19. Brain Behav Immun 2020. doi:10.1016/j.bbi.2020.04.017

5 Zhao H, Shen D, Zhou H, et al. Guillain-Barré syndrome associated with SARS-CoV-2 infection: causality or coincidence? Lancet Neurol 2020;19:383-4.

6 Beyrouti R, Adams ME, Benjamin L, et al. Characteristics of ischaemic stroke associated with COVID-19. J Neurol Neurosurg Psychiatry 2020;91:898-900.

7 Solomon T, Michael BD, Smith PE, et al. Management of suspected viral encephalitis in adults--Association of British Neurologists and British Infection Association National Guidelines. J Infect 2012;64:347-73.

8 Hill $A B$. The environment and disease: association or causation? Proc $R$ Soc Med 1965;58:295-300.

9 Goenka A, Michael BD, Ledger E, et al. Neurological manifestations of influenza infection in children and adults: results of a national British surveillance study. Clin Infect Dis 2014;58:775-84.

10 Netland J, Meyerholz DK, Moore S, et al. Severe acute respiratory syndrome coronavirus infection causes neuronal death in the absence of encephalitis in mice transgenic for human ACE2. J Virol 2008;82:7264-75.

11 Arabi YM, Harthi A, Hussein J, et al. Severe neurologic syndrome associated with Middle East respiratory syndrome corona virus (MERS-CoV). Infection 2015;43:495-501. 